[Agr. Biol. Chem., Vol. 33, No. 10, p. 1507 1516, 1969]

\title{
Biosynthesis of Piericidins A and B by Streptomyces mobaraensis
}

\author{
By Yasuo Kimura, Nobutaka Takahashi and Saburo Tamura \\ Department of Agricultural Chemistry, The University of Tokyo, \\ Bunkyo-ku, Tokyo \\ Received May 9, 1969
}

\begin{abstract}
Biosynthesis of piericidins $\mathrm{A}$ and $\mathrm{B}$ (PA and $\mathrm{PB}$ ) has been investigated using ${ }^{14} \mathrm{C}$-labeled compounds. Incorporation ratios of DL-methionine(methyl-14 $\mathrm{C}$ ), propionate-1-14 $\mathrm{C}$ and acetate$1-14 \mathrm{C}$ and $-2-14 \mathrm{C}$ were $7.4,4.5,1.2$ and $0.9 \%$, respectively, whereas DL-mevalonic lactone${ }^{2}{ }^{14} \mathrm{C}$ and formate-14 $\mathrm{C}$ were not incorporated. Degradation studies on labeled PA show that in the biosynthesis of piericidins a long branched $\mathrm{C}_{23}$-chain was formed from five propionate and four acetate units and then a nitrogen atom was introduced at the terminal part of the chain, followed by cyclization to form the pyridine ring. The two methoxyl groups on the rings of $\mathrm{PA}$ and $\mathrm{PB}$ as well as the one in the side chain of $\mathrm{PB}$ were derived from S-methyl of methionine.
\end{abstract}

Piericidins $\mathrm{A}^{\mathrm{n}}$ and $\mathrm{B}^{1,2 \dagger}$ (PA and $\mathrm{PB}$ ) are natural insecticidal substances isolated from mycelia of Streptomyces mobaraensis Nagatsu et Suzuki and their structures have been elucidated as $\mathrm{Ia}^{3 \prime}$ and $\mathrm{Ib}^{2 !}$ respectively. They possess marked toxicity against several species of insects, aphids and mites. Moreover, they show specific inhibitory activity ${ }^{4}$ for electron transport system in mitochondoria.

Though several papers have been published up to the present on biosynthetic mechanisms of branched aliphatic chains ${ }^{5}$ and pyridine rings, ${ }^{6}$ studies on the biosynthesis of such compounds as piericidins, which are composed of a poly-substituted pyridine ring and a long branched aliphatic chain, have never been

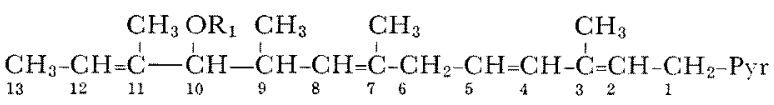

$$
\begin{array}{ll}
\text { Ia: } & \mathrm{R}_{1=\mathrm{R}_{2}=\mathrm{H}} \\
\text { Ib: } & \mathrm{R}_{1}=\mathrm{CH}_{3}, \mathrm{R}_{2}=\mathrm{H} \\
\text { II: } & \mathrm{R}_{1}=\mathrm{R}_{2}=\mathrm{COCH}_{3}
\end{array}
$$

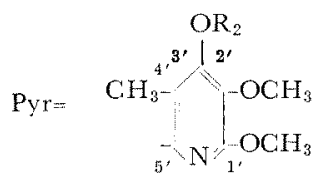

1) S. Tamura, N. Takahashi, S. Miyamoto, R. Mori, S. Suzuki and J. Nagatsu, Agr. Biol. Chem., 27, 576 (1963)

2) N. Takahashi, A. Suzuki, Y. Kimura, S. Miyamoto and S. Tamura, Tetrahedron Letters, 1967, 1961; N. Takahashi, A. Suzuki, Y. Kimura, S. Miyamoto, S. Tamura, T. Mitsui and J. Fukami, Agr. Biol. Chem., 32, 1115 (1968)

3) N. Takahashi, A. Suzuki and S. Tamura, J. Am. Chem. Soc., 87, 2066 (1965); N. Takahashi, A Suzuki and S. Tamura, Agr. Biol. Chem., 30, 1 (1966).

4) C. Hall, M. Wu, F. L. Crane, N. Takahashi,
S. Tamura and K. Folkers, Biochem. Biophys. Res. Commun., 25, 373 (1966)

5) cf. A. J. Birch, Simonsen Lecture, Proc. Chem. Soc., 1962, 3; A. J. Birch, R. J. English, R. A. MassyWestropp and H. Smith, $J$. Chem. Soc., 1958, 369; A. J. Birch, P. Fitton, E. Pride, A. J. Ryan, H Smith and W. B. Whalley, $J$. Chem. Soc., 1958, 4576 .

6) cf. E. Leete, Science, 147, 1000 (1968); H. Ogawara, K. Maeda and $H$. Umezawa, Biochem., 1968, 3296; N. Ogawara, J. L. R. Chandler, T. K. Gholson, R. J. Rosser and A. J. Andreoli, Biochem. Biophys. Acta, 141, 199 (1967). 
disclosed yet. This fact prompted us to investigate the biosynthesis of piericidins by the microorganism.

At first composition of culture medium was investigated and then culture phase for the addition of ${ }^{14} \mathrm{C}$-precursors was examined in order to find the best condition for the incorporation. $\mathrm{C}_{4}$ - and $\mathrm{K}_{4}$-media shown in Table IV were found to be suitable for seed culture and piericidin production, respectively.

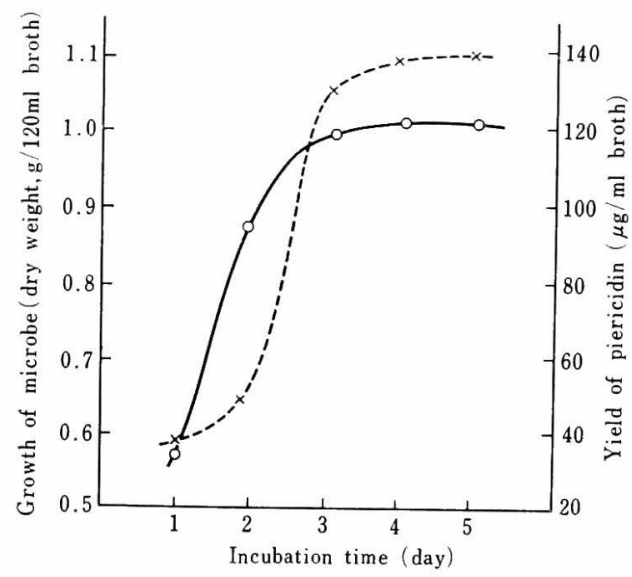

FIG. 1. Relationship between Growth of Streptomyces mobaraensis and Yield of Piericidin.

$\bigcirc-\bigcirc$ Growth, $\times---x$ Yield
Fig. 1. The dry weight increased quickly on the second day after innoculation, while the yield increased on the third day. Therefore, the labeled precursors were administrated on the third day into $\mathrm{K}_{4}$-medium and the culti-

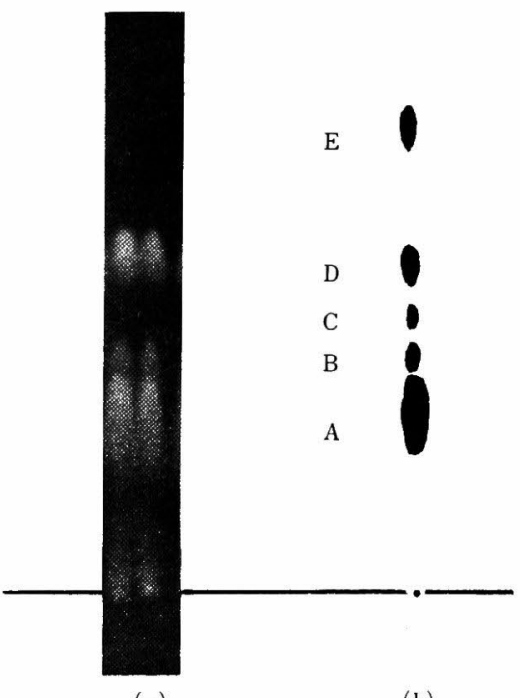

(a)

(b)

FIG. 2. Radioautogram and Thin Layer Chromatogram of Hexane Fraction Containing Piericidins.

(a), radioautogram; (b), thin layer chromatogram developed with the Dragendorff's reagent. A, PA; B, PC; C, Unknown; D, PB; E, Unknown.

TABLE I. InCORPoRAtion Ratios of ${ }^{14} \mathrm{C}$-PRECURSORS INTO PIERICIDIN A

Acetic acid-1-14 $\mathrm{C}$

Acetic acid-2-14 $\mathrm{C}$

L-Aspartic acid-14 $\mathrm{C}(\mathrm{U})$

Formic acid- ${ }^{14} \mathrm{C}$

Glycine-14C (U)

DL-Methionone (methyl-14 $\mathrm{C}$ )

DL-Mevalonic lactone-2-14 $\mathrm{C}$

Propionic acid-1-14 $\mathrm{C}$

L-Serine $-{ }^{14} \mathrm{C}$ (U)
Specific activity
$\mathrm{mC} / \mathrm{mM}$

22.2

20.2

143.0

13.2

25.0

5.77

4.82

19.5

99.0

\section{Incorporation}

$\%$

0.9

1.2

0.5

0.00

0.28

7.4

0.02

4.5

0.52

Changes of the dry weight of mycelia and yield of piericidins during the course of cultivation at $26.5^{\circ} \mathrm{C}$ in $\mathrm{K}_{4}$-medium are shown in

vation was continued for an additional two days.

Thin layer chromatogram and radioauto- 
gram of crude piericidins obtained from the culture broth fed with propionate- $1-{ }^{14} \mathrm{C}$ are shown in Fig. 2. Strong radio activity was detected at the spot corresponding to PA, but spots of $\mathrm{PB}$ and $\mathrm{PC}^{*}$ showed weaker activity.

Incorporation ratios of various labeled precursors into PA are summarized in Table I. Administrations of propinate- $1-{ }^{14} \mathrm{C}$ and $\mathrm{DL}^{-}$ methionine (methyl $-{ }^{14} \mathrm{C}$ ) afforded $\mathrm{PA}$ with very high activity, incorporations being 4.5 and $7.4 \%$, respectively, while incorporations of acetate $-1-{ }^{14} \mathrm{C}(0.9 \%)$ and $-2-{ }^{14} \mathrm{C}(1.2 \%)$ were rather low. Formate $-{ }^{14} \mathrm{C}$ and $\mathrm{DL}$-mevalonic lactone-2- ${ }^{14} \mathrm{C}$ were not incorporated.

Woodward" proposed that branching methyl groups in the molecules of macrolides, the characterisic metabolites of Streptomycetes, have origin in $\mathrm{C}-3$ of propionates residue incorporated as intact units. This suggestion was confirmed by the degradation reactions of labeled erythromycin, ${ }^{81}$ magnamycin" and methymycin. ${ }^{10)}$ Further, utilization of propionic acid was shown in the biosynthesis of branched chain fatty acids by Ascaris lumbticoides, ${ }^{111}$ Mycobacteria $^{121}$ and preen gland of goose. ${ }^{13}$ The high incorporation ratio of propionate-1${ }^{14} \mathrm{C}$ into PA mentioned above suggests that this compound is produced via the poly ketide route in the manner similar to that for macrolides and branched chain fatty acids.

DL-Methionine (methyl- ${ }^{14} \mathrm{C}$ ) showed the high-

* PC (piericidin C) is a minor component among piericidin homologs (unpublished)

7) R. B. Woodward, Angew. Chem., 69, 50 (1957).

8) H. Grisebach, H. Achenbach and W. Hofheinz, Z. Nasurforsch., 15b, 560 (1960); T. Kaneda, J. C. Butte, S. B. Taubman and J. W. Corcoran, J. Biol. Chem., 237, 322 (1962)

9) H. Achenbach and H. Grisebach, Z. Naturforsch., 19b, 561 (1964); D. Srinivasan and P. R. Srinivasan, Biochem., 6, 3111 (1967).

10) A. J. Birch, C. Djerassi, J. D. Dutcher, J. Majer, D. Perlman, E. Pride, R. W. Rickards and P. J. Thompson, J. Chem. Soc., 1964, 5274.

11) J. H. Saz and A. Weil, J.Biol. Chem., 237, 2053 (1962).

12) E. Lederer, Angew. Chem., 76, 241 (1964); I. Yano and M. Kusunose, Biochem. Biophys. Acta, 116, 593 (1966); M. Gastambide-Odier, J. M. Delaumeny and $\mathrm{H}$. Kuntzel, ibid., 125, 33 (1966).

13) R. E. Noble, R. L. Stjernholm, D. Mercier and E. Lederer, Nature, 199, 600 (1963). est incorporation among labeled precursors tested. This suggests that methoxyl groups in the pyridine ring are derived from S-methyl of methionine as in the case of biosynthesis of novobiocin. ${ }^{141}$ On the other hand, the negligible incorporation of DL-mevalonic lactone- $2-{ }^{14} \mathrm{C}$ into $\mathrm{PA}$ is compatible with the well-known observation that mevalonate is not incorporated into metabolites produced by Streptomyces species.

Degradation experiments were carried out according to the scheme shown in Figs. 3 and 4 to find the distribution of radioactivity in the labeled PA molecule. Percent distribution in the degradation products are summarized in Tables II and III.

The distribution of activities in the degradation products from propionate-labeled PA indicates that five propionate units were incorporated into PA. Compounds VII and VIII obtained from octahydro PA diacetate (III) retain $80 \%$ of activity, whereas compounds $\mathrm{IV}, \mathrm{Vb}$ and VIa from PA diacetate (II) contain 40,40 and $20 \%$ of activity, respectively. The percent activity retained in $\mathrm{Vb}$ and VIa, together with the $20 \%$ loss of activity in the degradation from III to VII and VIII, suggests that $\mathrm{C}-2$ (in the side chain) and $\mathrm{C}-3^{\prime}$ (in the pyridine ring) should originate from C-1 of propionate. Moreover, the specific activity in IV indicates that this compound should be constructed from two propionate units and that $\mathrm{C}-8$ and $\mathrm{C}-10$ in the side chain correspond to $\mathrm{C}-1$ of propionate. The negligible activity in acetaldehyde obtained from II indicates that $\mathrm{C}-12$ and $\mathrm{C}-13$ may be derived from acetate. Although evidence for the origin of $\mathrm{C}-4 \sim \mathrm{C}-7$ was not available, comparison of the specific activities among IV. $\mathrm{Vb}$ and VIII suggests that $\mathrm{C}-6$ most likely originates from $\mathrm{C}-1$ of propionate. These results show that propionates were incorporated as intact units and that $\mathrm{C}-2, \mathrm{C}-6, \mathrm{C}-8, \mathrm{C}-10$

14) A. J. Birch, D. W. Cameron, P. W. Holloway and R. W. Rickards, Tetrahedron Letters, 1960, 26. 


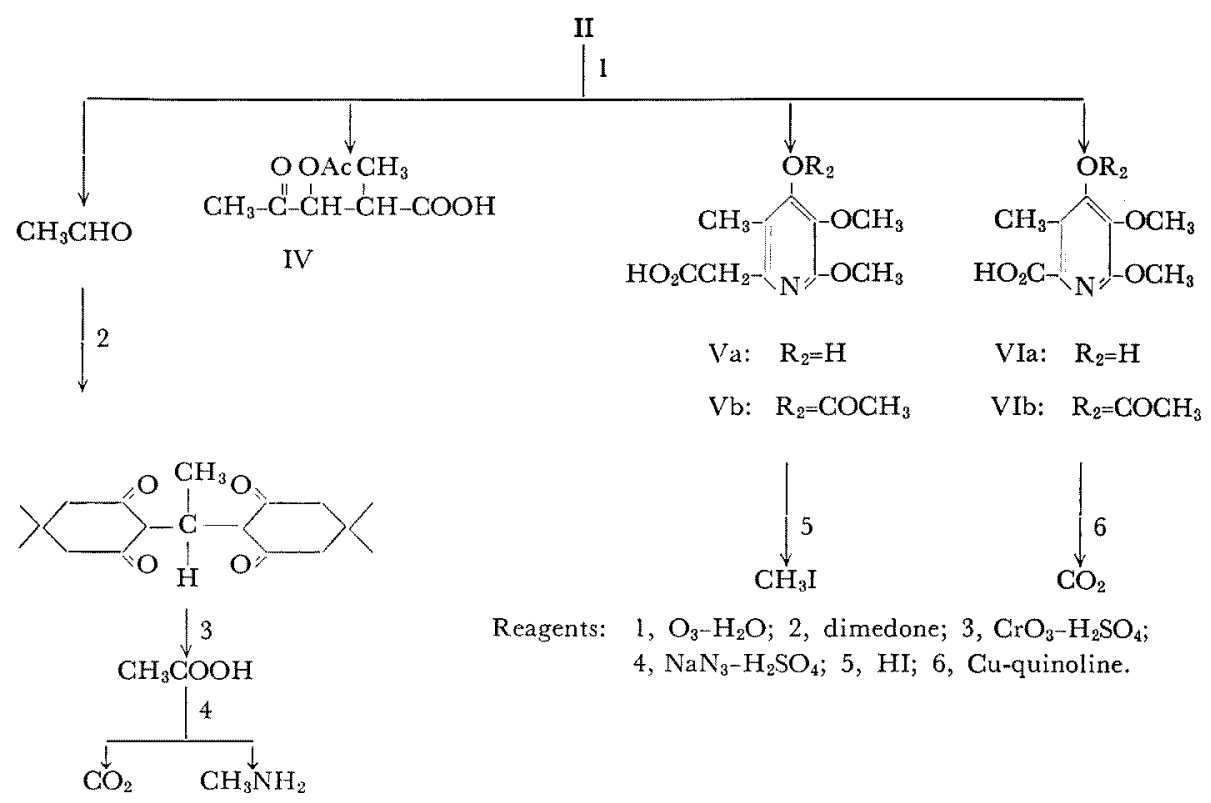

FIG. 3.



FIG. 4. 
Table II. Percentage Distribution of Radioactivity in Degradation Products of Piericidin a labeled with Propionate or Methionine as a Precursor



Table III. Percentage Distribution of Radioactivity in Degradation Products of Piericidin A LABeled WiTh ACETATE-1-14G OR ACETATE-2-14 C AS A PRECURSOR

\begin{tabular}{|c|c|c|c|c|c|c|}
\hline & \multicolumn{3}{|c|}{ Acetate- $1-{ }^{14} \mathrm{C}$} & \multicolumn{3}{|c|}{ Acetate-2-14C } \\
\hline & $10^{4} \mathrm{dpm} / \mathrm{mm}$ & $0_{0}^{*}$ & $9 * *$ & $10^{4} \mathrm{dpm} / \mathrm{mM}$ & $\%^{*}$ & $\mathscr{6}^{* *}$ \\
\hline II & 62.8 & 100 & 100 & 95.0 & 100 & 100 \\
\hline IV & 4.0 & 6.4 & 0.0 & 19.7 & 20.7 & 0.0 \\
\hline $\mathrm{Vb}$ & 30.5 & 48.5 & 50.0 & 37.6 & 39.6 & 50.0 \\
\hline VIa & 29.5 & 47.0 & 50.0 & 33.2 & 35.0 & 50.0 \\
\hline $\mathrm{BaCO}_{3}(\mathrm{C}-1)$ & - & & & 11.7 & 12.3 & 25.0 \\
\hline $\mathrm{CH}_{3} \mathrm{CHO}$ & 11.7 & 18.7 & 25.0 & 11.7 & 12.3 & 25.0 \\
\hline $\mathrm{CH}_{3} \mathrm{NH}_{2}(\mathrm{C}-13)$ & 0.4 & 0.6 & 0.0 & 11.1 & 11.7 & 25.0 \\
\hline $\mathrm{BaCO}_{3}(\mathrm{C}-12)$ & 11.4 & 18.1 & 25.0 & 0.6 & 0.6 & 0.0 \\
\hline VII & 60.6 & 96.5 & 100 & - & & \\
\hline $\mathrm{BaCO}_{3}\left(\mathrm{C}-\mathrm{I}^{\prime}\right)$ & 12.8 & 20.4 & 25.0 & - & & \\
\hline VIII & 47.4 & 75.5 & 75.0 & - & & \\
\hline
\end{tabular}

in the side chain and $\mathrm{C}-3^{\prime}$ in the pyridine ring came from $\mathrm{C}-1$ of propionate.

As already mentioned, the incorporation of acetate-1 $1{ }^{14} \mathrm{C}(c a ., 0.8 \%)$ and $-2 \cdot{ }^{14} \mathrm{C}(c a ., 1.2 \%)$ into $\mathrm{PA}$ was lower than that of propionate$1-{ }^{14} \mathrm{C}(c a ., 4.5 \%)$. However, in the degradation studies on acetate-labeled $\mathrm{PA}$, radioactivity was found even in the structural part having its origin in propionate, the percent distribution of IV being $6.4 \%$ on acetate- $1-{ }^{14} \mathrm{C}$ labeling and $20.7 \%$ on acetate- $2-{ }^{14} \mathrm{C}$ labeling, respectively. Randomization of this type caused by acetates has been shown in the biosynthesis of macrolides, such as methymycin and eryth- romycin, and its mechanism has been elucidated by several investigators. ${ }^{10,15}$ As shown in Fig. 5, acetic acid reacts with oxaloacetic acid to afford citric acid which is converted to succinyl-CoA ${ }^{(6)}$ through several steps. Then, succinyl-CoA rearranges to methylmalonyl$\mathrm{CoA}^{17,18}$ (process $\mathrm{A}$ ) to be incorporated in

15) H. Grisebach, W. Hofheinz and H. Achenbach, Naturwiss., 48, 101 (1961).

16) H. L. Kornberg, Annu. Rev. Microbiol., 13, 49 (1959).

17) H. Eggerer, E. R. Stadtman, P. Overate and U. F, Lynin, Biochem. Z., 331, I (1960).

18) W. S. Beck and S. Ochoa, J. Biol. Chem., 232, 931 (1958). 
poly ketide chain. At the same time succinyl-CoA partially recycles in the TCA cycle (process $\mathrm{B}$ ).

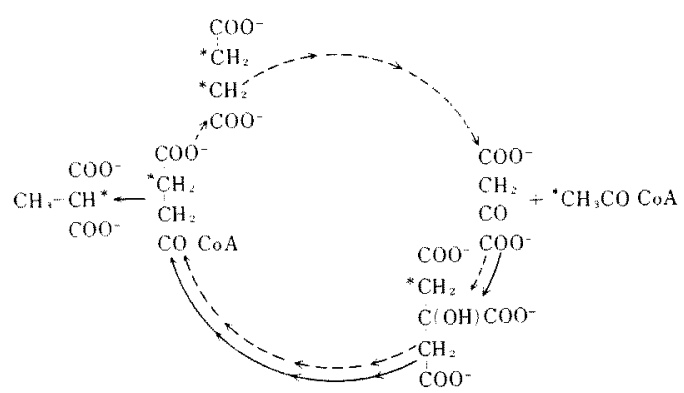

FIG. 5. Metabolic Pathway of Acetyl-CoA.

Process A
$\ldots$ Process B

It is noteworthy that the incorporation ratio of acetate- $1-{ }^{14} \mathrm{C}$ into PA was lower than that of acetate- $2-{ }^{14} \mathrm{C}$ and that the ratio of the percentage distribution of III to acetaldehyde in the case of acetate- $1{ }^{14} \mathrm{C}$ labelling was much lower than that for acetate- $2-{ }^{14} \mathrm{C}$ labelling. This may be explained in the following way. As shown in process $A$, the radioactivity of acetate- $1{ }^{14} \mathrm{C}$ is lost by decarboxylation of methylmalonyl-CoA, while that of acetate- $2-{ }^{14} \mathrm{C}$ is retained. In the process $B$, the conversion ${ }^{19}$ of succinyl-CoA to succinate changes the labeling pattern of isotopic distribution in two carboxyl carbons from acetate- $1{ }^{14} \mathrm{C}$ and in two methylene carbons from acetate $-2-{ }^{14} \mathrm{C}$, since succinate is a symmetrical molecule. The whole process may cause much higher incorporation of $\mathrm{C}-2$ of acetate into propionate unit than that of $\mathrm{C}-1$.

In spite of these randomizations, the regularity in the incorporation of labeled acetates into probable acetic acid units was recognized. Thus specific activities of $\mathrm{C}-1$ (12.3\%, $\mathrm{CO}_{2}$ from $\mathrm{V}$ ) and $\mathrm{C}-13$ (11.7\%, methylamine from acetaldehyde) of PA labeled with acetate- $2-{ }^{14} \mathrm{C}$

19) S. Weinhouse and R. H. Millington, J. Am. Chem. Soc., 69, 3089 (1947); J. A. DeMoss and H. E. Swim, J. Bacteriol., 74, 445 (1957). and those of $\mathrm{C}_{-1} \mathrm{1}^{\prime}\left(20.4 \%, \mathrm{CO}_{2}\right.$ from VII) and $\mathrm{C}-12$ (18.1\%, $\mathrm{CO}_{2}$ from acetaldehyde) of PA from acetate- $1-{ }^{14} \mathrm{C}$ were almost the same.

The radioactivity in PA labeled with DLmethionine (methyl $-{ }^{14} \mathrm{C}$ ) was almost exclusively located in the pyridine moiety $(\mathrm{Vb})$ and detected in methyl iodide evolved from VIa by the Zeisel reaction. This indicates the occurrence of O-methylation at $\mathrm{C}-1^{\prime}$ and $\mathrm{C}-2^{\prime}$ but not $\mathrm{C}$-methylation during the biosynthesis.

Incorporation of labeled aspartate and serine was low, and extensive radomization was observed in degradation products. This may be explained by the formation of acetate from aspartate via alanine and pyruvate, and serine via pyruvate.

All evidences above cited suggest that in the biosynthesis of PA a long branched $\mathrm{C}_{23}$ chain was formed from four acetate and five propionate units. In other words, this would mean that successive linkages of CoA's occurred in the order of an acetyl-, three methylmalonyl-, a malonyl-, methylmalonyl-, a malonyl-, a methylmalonyl and a malonylCoAs. Then one nitrogen atom was incorporated at the terminal part of the chain followed by cyclization to form the pyridine ring. After introduction of oxygen in the pyridine ring, O-methylation might occur by methionine. This demonstrates a novel type of biosynthesis for pyridine ring.

As shown earlier, ${ }^{2)} \mathrm{PB}$ is produced at the later stage of the fermentation, suggesting its formation from PA. PA labeled with propionate- $1-{ }^{14} \mathrm{C}$ was added to the culture which has been pre-cultivated without isotopic precursors and the fermentation was continued for an additional two weeks. PB thus obtained was shown to be labeled, incorporation being 9.5\%. Since considerable amount of PA had already been produced till the stage of administration of labeled PA and besides the ratio of yield for $\mathrm{PA}$ and $\mathrm{PB}$ was almost $1: 1$ at the final stage of the fermentation, ${ }^{21}$ the real incorporation of $\mathrm{PA}$ into $\mathrm{PB}$ should be much higher. When DL-methionine(methyl- 
$\left.{ }^{14} \mathrm{C}\right)$ was incubated with non-labeled PA, $2.7 \%$ of isotope was incorporated into $\mathrm{PB}$, indicating that O-methylation of the $\mathrm{C}-10$ hydroxyl of PA occurs at the stage different from that for $\mathrm{C}-6^{\prime}$ and $\mathrm{C}-7^{\prime}$ methylation in the pyridine ring. Thus biosynthetic pathway of PA and $\mathrm{PB}$ is summarized as shown in Fig. 6.
${ }^{14} \mathrm{C}$-Labeled compounds. Acetate- $1-14 \mathrm{C}$ and $-2-{ }^{14} \mathrm{C}$, propionate-1-14C, DL-methionine (methyl-14 $\mathrm{C}$ ), formate- ${ }^{14} \mathrm{C}$, DL-mevalonic lactone-2- ${ }^{14} \mathrm{C}, \mathrm{L}-$ serine-U $-{ }^{14} \mathrm{C}$ and L-aspartic acid-U-14 $\mathrm{C}$ were purchased from Daiichi Pure Chemicals Co., Ltd.

Radioactivity measurement. The activities of the samples were determined by a Packard liquid scintil-

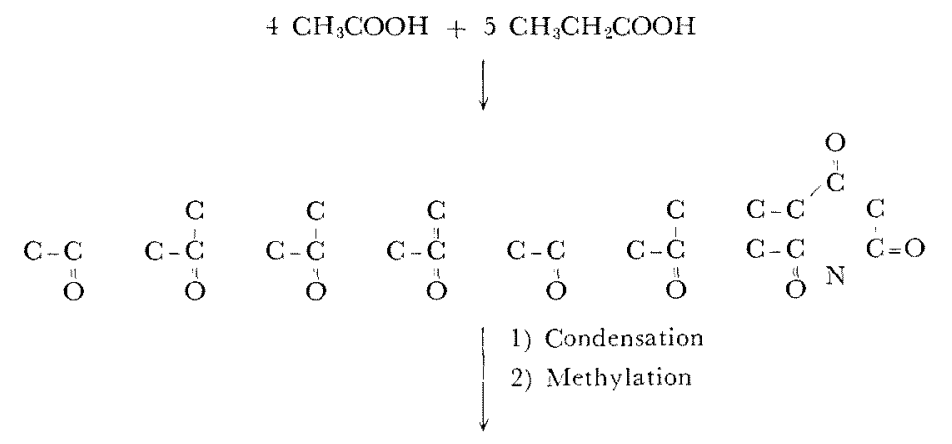
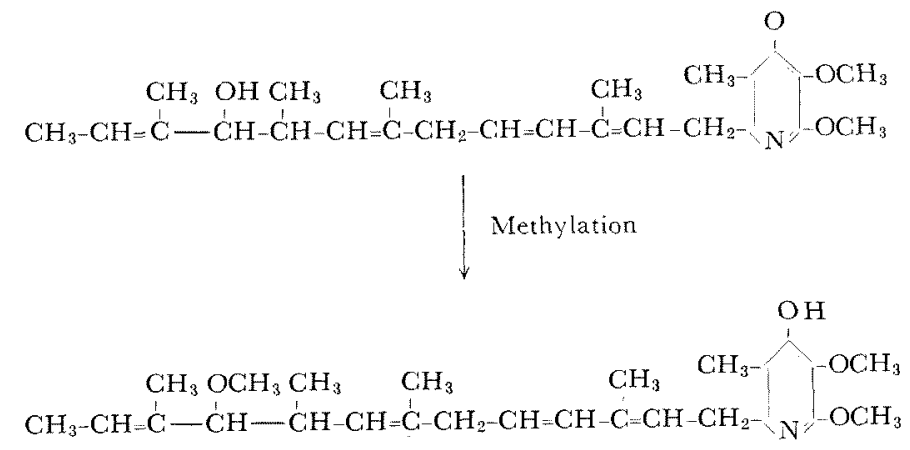

FIG. 6.

\section{EXPERIMENTAL}

Melting points were determined on a Kofler block without cerrection. Ultraviolet spectra were measured in methanol with a Cary 14 spectrophotometer. Infrared spectra were taken on a JASCO IR-S spectrophotometer as liquid films or nujol mulls. NMR spectra were measured in deuterochloroform solutions by a JMN-4H-100 spectrometer and chemical shifts were expressed in $\delta$-value(ppm) from tetramethylsilane as the internal standard. lation counter, 314 AX or Baird, 245. The scintillation mixture was consisted of toluene $(1000 \mathrm{ml}), 2$, 5-diphenyl-oxazole (PPO) (4 g) and 1, 4-bis [2-(5phenyloxazolyl)] benzene (POPOP) $(100 \mathrm{mg})$. Radioactivity of $\mathrm{CO}_{2}$ was measured as barium carbonate in the above toluene scintillater containing Cab-O-Sil$M 5^{\prime}(4,6)$.

Radioautography of thin layer chromatography. Thin layer chromatography was carried out with silica gel $G$ (Merck) as adsorbent and benzene-ethyl acetate (93:7) as solvent. After chromatographic development, the plate was exposed to a Fuji X-ray film for two days 
for radioautography.

Culture technique. Streptomyces mobaraensis was grown on an agar slant of Bennet's medium or potato medium. After five days' incubation at $26.5^{\circ} \mathrm{C}$ the microorganism was transfered into a $50 \mathrm{ml}$-test tube containing $10 \mathrm{ml}$ of $\mathrm{C}_{4}$-medium and incubated at $26.5^{\circ} \mathrm{C}$ for two days on a shaker. Then $10 \mathrm{ml}$ of the seed culture was transfered into a $500 \mathrm{ml}$-shaking flask containing $120 \mathrm{ml}$ of $\mathrm{K}_{4}$-medium. After cultivation at $26.5^{\circ} \mathrm{C}$ for two days on a rotary shaker, the radioactive compound was added and incubation was continued for an additional two days. adsorbent and benzene-ethyl acetate (93:7) as solvent, and detected as dark shadow under ultraviolet light

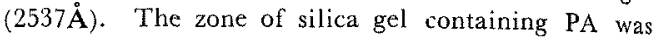
pulverized in a $30 \mathrm{ml}$-Erlenmeyer flask and extracted with methanol or acetone. The extract was evaporated to dryness under reduced pressure and the residual oil was dissolved in hexane. Evaporation of the sol. vent yielded about $10 \mathrm{mg}$ of pure PA. A small amount of $\mathrm{PB}$ was separated from PA through silica gel thin layer chromatography.

Preparation of labeled $P B$. 1) Streptomyces mobaraensis was grown on $\mathrm{K}_{4}$-medium at $26.5^{\circ} \mathrm{C}$. PA (labeled

TABle IV. COMPosition OF CULTURE MEdia For streptomyces mobaraensis

\begin{tabular}{lccc}
\multicolumn{4}{c}{$\mathrm{C}_{4}$-Medium (for seed culture) } \\
Glucose & $20 \mathrm{~g}$ & Soybeen powder & \\
Starch & 10 & Meat extracts & $25 \mathrm{~g}$ \\
$\mathrm{NaCl}$ & 2 & Brewing yeast & 10 \\
$\mathrm{~K}_{2} \mathrm{HPO}_{4}$ & 0.05 & Water & 10 \\
& $\mathrm{~K}_{4}$-Medium & (for piericidin production) \\
Glucose & $20 \mathrm{~g}$ & NaCl & $2 \mathrm{~g}$ \\
Peptone $_{\mathrm{K}_{2} \mathrm{HPO}_{4}}$ & 5 & Water & $1.0 \mathrm{liter}$ \\
& 2 & &
\end{tabular}

Determination of piericidin in the culture broth. Piericidin was assayed by antimicrobial activity against Xanthomonas oryzae. Test solution was prepared by mixing the culture filtrate with the residual aqueous solution after evaporation of acetone extract of mycelia. The assay was conducted by the cylinder-plate agar diffusion method. The composition of the culture medium for Xanthomonas oryzae is as follows: Na glutamate $(0.2 \%), \mathrm{K}_{2} \mathrm{HPO}_{4}(0.2 \%), \mathrm{MgCl}_{2}(0.10)$, $\mathrm{FeSO}_{4}$ $(0.01 \%)$, sucrose $(2.00 \%)$, yeast extract $(0.20)$, peptone $(0.50)$ and agar $(1.50)$.

Isolation of piericidins $A$ and $B$. Isolation was carried out according to the original literature ${ }^{1}$ with some modifications described here. The mycelia separated from $120 \mathrm{ml}$ of cultured broth by filtration were extracted with three $50 \mathrm{ml}$-portions of acetone, and the combined extracts were evaporated under reduced pressure. The residual aqueous solution was combined with the filtrate and extracted with two $50 \mathrm{ml}$-portions of ethyl acetate. The ethyl acetate extracts were successively purified through the methods described previously to give crude piericidins. Piericidins thus obtained were subjected to preparative thin layer chromatography with silica gel $\mathrm{GF}_{254}$ as with propionate- $1-14 \mathrm{C} ; 5.0 \mathrm{mg} ; 5.98 \mu \mathrm{C}$ ) was added on the third day after innoculation of the microbe and the fermentation was run for an additional ten days. Then labeled PB (5.4 mg; $0.57 \mu \mathrm{C} ; 9.53 \%$ ) was isolated in the usual way. 2) DL-Methionine (methyl-14 C) (spec. ac., $5.77 \mathrm{mC} / \mathrm{mm} ; 2.5 \mu \mathrm{C}$ ) was added to the pre-cultivated broth of Streptomyces mobaraensis on the fifth day after incubation together with non-labeled PA $(10 \mathrm{mg})$ and incubation was continued for an additional ten days. Labeled $\mathrm{PB}(5.1 \mathrm{mg}$; $0.068 \mu \mathrm{C} ; 2.796$ ) was isolated in the usual way.

\section{Degradation reactions}

a) Ozonolysis of PA diacetate. Ozone-enriched oxygen was passed through a solution of $1.63 \mathrm{~g}$ of PA in $50 \mathrm{ml}$ of pure chloroform at $-60^{\circ} \mathrm{C}$ until the color of the solution changed to pale blue. Then the half volume (solution A) of the reaction mixture was removed and ozonization was continued on another half at $-20^{\circ} \mathrm{C}$ until permanent blue color appeared (solution B). Solutions A and B were treated separately in the following way. The residual oily ozonides obtained on evaporation of chloroform under reduced pressure were decomposed with boiling water for 30 min and the aqueous solutions thus obtained were 
subjected to steam distilation, $250 \mathrm{ml}$ of distillate being collected. Residual aqueous solution was extracted with ethyl acetate to give an acidic fraction in the usual way.

The extract from solution $\mathrm{A}$ was applied to silicic acid column chromatography. Elution with benzene gave $\mathrm{Vb}$ and that with benzene-butanol (99:1) afforded Va. IV was obtained from the eluate with benzene-butanol (98:2). Va, $\mathrm{Vb}$ and IV were recrystallized from benzene-hexane to give crystals showing mp $157 \sim 158^{\circ} \mathrm{C}, \quad 113^{\circ} \mathrm{C}$ and $94^{\circ} \mathrm{C}$, respectively. The extract from solution $\mathrm{B}$ was purified through silicic acid column. Elution with benzene-butanol (98.5:1.5) gave VIa and VIb and that with benzenebutanol (98:2) yieled IV.

Anal. of VIa. (mp 169 $\sim 170^{\circ} \mathrm{C}$ ). Found: C, 51.17; $\mathrm{H}, 5.23 ; \mathrm{N}, 6.54$. Calcd. for $\mathrm{C}_{9} \mathrm{H}_{11} \mathrm{NO}_{5}$; C, 50.70; $\mathrm{H}, 5.20 ; \mathrm{N}, 6.57 \% . \nu_{\max }^{\mathrm{Nujol}} \mathrm{cm}^{-1}: 3300,1750,1605$, $1570,1330,1200,1135,1065,765 . \quad \lambda_{\max }^{\mathrm{CH}_{3} \mathrm{OH}} \mathrm{m} \mu(\varepsilon)$; $275(5100) .2 \mathrm{MeCl}_{3} 2.55(3 \mathrm{H}, \mathrm{Si}), 3.93(3 \mathrm{H}, \mathrm{s}), 3.95$ $(3 \mathrm{H}, \mathrm{s})$.

Anal. of VIb (mp 157 158 C). Found: $\mathrm{C}, 52.17 ; \mathrm{H}$, 5.14; N, 5.39. Calcd. for $\mathrm{C}_{11} \mathrm{H}_{13} \mathrm{NO}_{6}: \mathrm{C}, 51.76 ; \mathrm{H}$, $5.13 ; \mathrm{N}, 5.49 \% \cdot \nu_{\max }^{\mathrm{Nujol}} \mathrm{cm}^{-1}: 3350,1760,1720,1605$, $1570,1300,1200,1120,1050,730 . \lambda_{\max }^{\mathrm{CH}_{3} \mathrm{OH}} \mathrm{m} /(\varepsilon):$ $235(5500), 290$ (6100). ${ }_{0}^{\mathrm{CDCl}_{3}} \mathrm{Me}_{4}: 2.35(3 \mathrm{H}$, s) 2.50 $(3 \mathrm{H}, \mathrm{s}), 3.95(3 \mathrm{H}, \mathrm{s}), 4.05(3 \mathrm{H}, \mathrm{s})$.

b) Isolation of dimetone acetaldehyde. ${ }^{201}$ To a solution of $250 \mathrm{mg}$ of dimedone in $10 \mathrm{ml}$ of ethanol was added the $500 \mathrm{ml}$ of distillate from the steam distillation of ozonides. The reaction mixture was stood overnight at room temperature with stirring. The resulting precipitates of dimedone acetaldehyde $(90 \mathrm{mg})$ were filtered and washed with cold $50 \%$ aqueous ethanol. Recrystallization from aqueous ethanol afforded colorless needles, mp $141 \sim 142^{\circ} \mathrm{C}$.

c) Kuhn-Roth oxidation of dimedone acetaldehyde. Dimedone acetaldehyde $(30 \mathrm{mg}$ ) was oxidized with the Kuhn-Roth reagent $\mathrm{t}^{21}$ on heating at $130^{\circ} \mathrm{C}$ for $90 \mathrm{~min}$. The reaction mixture was steam distilled to give 100 $\mathrm{ml}$ of distillate, which was neutralized with $0.1 \mathrm{~N}$ sodium hydroxide. The sodium salt obtained after evaporation of the solution was converted in the

20) E. C. Horning and M. G. Horning, J. Org. Chem., 11, 95 (1946).

21) E. J. Eisenbaun, S. M. McElvain and B. F. Aycock, J. Am. Chem. Soc., 75, 607 (1954). usual way to the p-bromophenacyl ester (21 mg). The ester was recrystallized from light petroleum. Mp $85 \sim 86^{\circ} \mathrm{C}$.

d) Demethylation of compound VIa. Into $3 \mathrm{ml}$ of $52 \%$ hydroiodic acid, $20 \mathrm{mg}$ of VIa and a drop of glacial acetic acid were added. The reaction mixture was heated under reflux for an hr. Methyl iodide evolved was collected at $-20^{\circ} \mathrm{C}$ and added to a solution of $50 \mathrm{mg}$ of 3-nitrophthalimide ${ }^{22}$ in $10 \mathrm{ml}$ of $\mathrm{N}, \mathrm{N}$-dimethylformamide. The mixture was stirred at room temperature for $100 \mathrm{~min}$. After addition of $20 \mathrm{ml}$ of benzene, the resulting mixture was poured into 100 $\mathrm{ml}$ of water. The benzene layer was separated and the residual aqueous phase was extracted with three $30 \mathrm{ml}$-portions of benzene. The combined benzene solutions were washed successively with $50 \mathrm{ml}$ of $0.2 \mathrm{~N}$ sodium hydroxide and $50 \mathrm{ml}$ of water and then dried over anhydrous sodium sulfate. The solvent was evaporated under reduced pressure to give crude $\mathrm{N}$-methyl-3-nitrophthalimide ( $26 \mathrm{mg}$ ), which was recrystallized from benzene-hexane to give colorless needles, $\mathrm{mp} 112 \sim 113^{\circ} \mathrm{C}$. Anal. Found: C, 52.59; H, 3.17; $\mathrm{N}, 13.62$. Calcd. for $\mathrm{C}_{9} \mathrm{H}_{6} \mathrm{O}_{4} \mathrm{~N}_{7}: \mathrm{C}, 52.43 ; \mathrm{H}, 2.93$; $\mathrm{N}, 13.59 \% . \delta_{\mathrm{Me}_{4} \mathrm{Sj}}^{\mathrm{CDCl}_{3}}: 3.20\left(3 \mathrm{H}, \mathrm{N}-\mathrm{CH}_{3}, \mathrm{~s}\right), 8.08(3 \mathrm{H}$, aromatic-H, $\mathrm{m}$ ).

e) Schmidt reaction on acetic acid. To a solution obtained by dissolving $20 \mathrm{mg}$ of sodium acetate in $1 \mathrm{ml}$ of concentrated sulfuric acid, was quickly added 100 $\mathrm{mg}$ of powdered sodium azide at $0^{\circ} \mathrm{C}$. Then the flask was connected to four traps in series, the first containing $20 \mathrm{ml}$ of $5 \%$ potassium permanganate in $0.5 \mathrm{~N}$ sulfuric acid and the remaining three $30 \mathrm{ml}$ of saturated barium hydroxide. A stream of $\mathrm{O}_{2}$ and $\mathrm{CO}_{2}$-free nitrogen gas was passed through the mixture. The reaction mixture was allowed to warm to room temperature and then heated to $80 \sim 100^{\circ} \mathrm{C}$ for $60 \mathrm{~min}$. The carbon dioxide evolved was collected as barium carbonate, which was filtered and successively washed with water, $990^{\circ}$ ethanol and ether.

Methylamine hydrochloride obtained from the acidic fraction on steam distillation of the reaction mixture was directly converted to the benzoyl derivative, which was recrystallized from ether-hexane. $\mathrm{Mp}_{\mathrm{P}} 85 \sim 86^{\circ} \mathrm{C}$.

f) Decarboxylation of compound VIa. To a solution of $20 \mathrm{mg}$ of Vla in $5 \mathrm{ml}$ of quinoline was added 50

22) P. P. T. Sah and T. S. Ma, Ber., 65, 1630 (1932). 
mg of copper powder. The reaction flask was connected to the same traps as those used in the Schmidt reaction. Then the mixture was heated in a salt bath at $250^{\circ} \mathrm{C}$ under a stream of $\mathrm{O}_{2}$ - and $\mathrm{CO}_{2}$-free nitrogen gas. The carbon dioxide evolved was collected as barium carbonate during $60 \mathrm{~min}$ in the usual way.

g) Decarboxylation of compound VII. Twenty $\mathrm{mg}$ of VII was dissolved in $1 \mathrm{ml}$ of ice-cold $18 \mathrm{~N}$ sulfuric acid in a flask equipped with the traps mentioned above. The reaction mixture was heated at $120^{\circ} \mathrm{C}$ for $60 \mathrm{~min}$. Barium carbonate was recovered in the usual way.

Acknowledgement. The authors wish to express their thanks to Kaken Chemical Co. for the supply of crude piericidin. They are also indebted to Mr. K. Aizawa of this Department for the measurement of IR and NMR spectra. 